SMIRNOV Vladimir Alexeevich, Ph.D. in Engineering, Associate Professor, Leading Research Officer of the Research and Educational Center «Nanomaterials and Nanotechnology», Moscow State University of Civil Engineering; Yaroslavskoye hw. 26, Moscow, Russian Federation, 129337, smirnov@nocnt.ru;

KOROLEV Evgenij Valerjevich, Doctor of Engineering, Professor, Director of the Research and Educational Center «Nanomaterials and Nanotechnology», Moscow State University of Civil Engineering; Yaroslavskoye hw. 26, Moscow, Russian Federation, 129337, korolev@nocnt.ru; EVSTIGNEEV Alexandr Viktorovich, postgraduate, Moscow State University of Civil Engineering; Yaroslavskoye hw. 26, Moscow, Russian Federation, 129337, aspirant@nocnt.ru

\title{
THE REVIEW OF THE MODELING METHODS AND NUMERICAL ANALYSIS SOFTWARE FOR NANOTECHNOLOGY IN MATERIAL SCIENCE ${ }^{2}$
}

Due to the high demand for building materials with universal set of properties which extend their application area the research efforts are focusing on nanotechnology in material science. The rational combination of theoretical studies, mathematical modeling and simulation can favour reduced resource and time consumption when nanomodified materials are being developed. The development of composite material is based on the principles of system analysis which provides for the necessity of criteria determination and further classification of modeling methods. In this work the criteria of spatial scale, dominant type of interaction and heterogeneity are used for such classification. The presented classification became a framework for analysis of methods and software which can be applied to the development of building materials. For each of selected spatial levels - from atomistic one to macrostructural level of constructional coarsegrained composite - existing theories, modeling algorithms and tools have been considered. At the level of macrostructure which is formed under influence of gravity and exterior forces one can apply probabilistic and geometrical methods to study obtained structure. The existing models are suitable for packing density analysis and solution of percolation problems at the macroscopic level, but there are still no software tools which could be applied in nanotechnology to carry out systematic investigations. At the microstructure level it's possible to use particle method along with probabilistic and statistical methods to explore structure formation but available software tools are partially suitable for numerical analysis

\footnotetext{
${ }^{2}$ This work is supported by the Ministry of Science and Education of Russian Federation, job No 2014/107, project title «Structure formation of sulfur composites: phenomenological and ab initio models»
} 
of microstructure models. Therefore, modeling of the microstructure is rather complicated; the model has to include potential of pairwise interaction. After the model has been constructed and parameters of pairwise potential have been determined, many software packages for solution of ordinary differential equations can be used. In the cases when pairwise forces depend not only on distance between surfaces of particles, the development of special-purpose algorithms and software is required. The investigation at lower spatial level can be done with help of quantum chemistry packages. In the middle between microstructural and atomistic levels there was a gap corresponding to the scale $1 \ldots 100 \mathrm{~nm}$. At this level properties of material are considerably affected by size; this fact is proposed to be considered when defining nanostructure of constructional composite. Today there are a lot of achievements in development of modeling methods and software; however, there are still several problems to be solved. The system approach to the analysis of problem, followed by selection of proper modeling methods, algorithms and software tools, is the key for design of new efficient building materials.

Key words: nanotechnology, constructional material science, disperse systems, computational chemistry, probabilistic models, molecular dynamics.

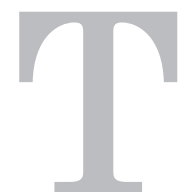

echniques and software tools for modeling and simulation - socalled «third method of research" - are widely used in different branches of science together with theoretical studies and experimental investigations; such techniques and tools are considered as equal alternative to theory and experiment $[1,2]$. This is because of the fact that decisions taken on the base of modeling and simulation allow significant reducing costs and resource consumptions during research and development process.

For decades numerical experiments have been used to design and analyze structures in civil engineering. On the contrary the development of construction materials is performed mainly by means of «traditional» methods - experimental studies combined with regression analysis, commonly referred to as «statistical modeling». Such situation is a natural consequence of complex character of building materials; there are multiple levels of heterogeneity which significantly complicate formulation and further analysis of the models. 
Such state of the modeling in constructional material science can not last any longer. Due to demand for building materials with unique complex of properties (including materials with controllable service lifetime [3]) the research efforts are focusing on modern methods of nanotechnology [4]. It is often too costly to design of nanoscale-structured and nanoscalemodified materials with "trial-and-error» approach, even if such approach is combined with some optimization methods applied to raw experimental data or constructed statistical model (approximation of raw data). The reduction of resource consumption during research and development is possible only in the case of changing the direction towards theoretical studies, modeling and simulation.

Fortunately, the constructional material science takes advantages of plethora of models, algorithms and software tools already developed in other branches of science - mostly in theory of condensed state ( «clean» models based on quantum mechanics; «ab initio" models). The application of phenomenological models [5-7] (which are only required to be consistent with both experiment and theory, but not to be derived from the theory entirely) is also highly efficient; in particular, such methods can be used for modeling of polymer matrix nanocomposites [7, 8].

The modeling process involves system analysis as a sound foundation. The examination of complex system is the decomposition process [1] where we initially split system in parts while minimizing both number of parts and number of cross-dependencies (which in fact are interactions) between them [2]. Yet before decomposition can be started the bounds for spatial scales of interest and corresponding list of possible interactions - which, in turn, define applicable modeling methods - should be fixed.

The selection of methods, algorithms and simulation software tools depends on characteristic scale of the system under examination. There can be several distinctive scales - from nanometer scale up to macroscopic level, and there are corresponding modeling methods (representing primary interactions between elements) most suitable for these scales. Depending on the characteristic size of the test system, different techniques of numerical analysis can be applied - methods based on quantum and classical mechanics; geometry and probability theory; continuum mechanics (Table 1).

The first row of Table 1 may correspond to distinctive spatial levels and reflects the fact that in some circumstances heterogeneous structure of constructional composite may be ignored. This fact is the fundamental 
Material science: Spatial scales and corresponding modeling methods

\begin{tabular}{|c|c|c|c|}
\hline Spatial scale & $\begin{array}{l}\text { Spatial level } \\
\text { characteristic }\end{array}$ & $\begin{array}{l}\text { Preferred theory } \\
\text { and models }\end{array}$ & $\begin{array}{c}\text { State of theory and presence } \\
\text { of modeling tools }\end{array}$ \\
\hline $\begin{array}{l}\text { Undefined } \\
\text { (several } \\
\text { scales) }\end{array}$ & $\begin{array}{l}\text { Heterogeneous } \\
\text { structure can be } \\
\text { ignored }\end{array}$ & $\begin{array}{l}\text { Continuum mechanics, finite } \\
\text { difference and finite element } \\
\text { representations. }\end{array}$ & $\begin{array}{l}\text { Detailed theory. Numerous } \\
\text { verified and certified } \\
\text { computation tools are } \\
\text { available. }\end{array}$ \\
\hline $\begin{array}{l}\text { More than } \\
0,1 \mathrm{~mm}\end{array}$ & Macrostructure & $\begin{array}{l}\text { Geometry of the system and } \\
\text { laying of elements may be } \\
\text { investigated with or without } \\
\text { Monte-Carlo method. Few } \\
\text { examples of dynamics } \\
\text { examination are known. }\end{array}$ & $\begin{array}{l}\text { Detailed theory (classical } \\
\text { mechanics), but computation } \\
\text { tools for constructional } \\
\text { material science either } \\
\text { unavailable or buggy. }\end{array}$ \\
\hline $0,1 \ldots 100 \mathrm{um}$ & Microstructure & $\begin{array}{l}\text { Particle systems with classical } \\
\text { mechanics, Monte-Carlo method } \\
\text { combined with analysis of } \\
\text { ensemble geometry. }\end{array}$ & $\begin{array}{l}\text { Detailed theory (classical } \\
\text { mechanics, physical chemistry, } \\
\text { thermodynamics, fracture } \\
\text { mechanics), numerous general- } \\
\text { purpose computation tools } \\
\text { for classical mechanics of } \\
\text { particle systems. Specific } \\
\text { software implementations for } \\
\text { constructional material science } \\
\text { still have to be developed. }\end{array}$ \\
\hline $1 \ldots 100 \mathrm{~nm}$ & $\begin{array}{l}\text { Area of size } \\
\text { effects in } \\
\text { disperse system; } \\
\text { Nanostructure }\end{array}$ & $\begin{array}{l}\text { Particle systems with classical } \\
\text { mechanics can be used in } \\
\text { conjunction with quantum } \\
\text { chemistry methods. Models for } \\
\text { Monte-Carlo and analysis of } \\
\text { ensemble geometry are mostly } \\
\text { unknown. }\end{array}$ & $\begin{array}{l}\text { Theory in active development, } \\
\text { numerous semi-empirical } \\
\text { models are known. Software } \\
\text { tools for neighbor spatial scales } \\
\text { can be utilized, but may be } \\
\text { unsuitable for constructional } \\
\text { material science. }\end{array}$ \\
\hline $0,1 \ldots 1 \mathrm{~nm}$ & Atomistic level & Quantum chemistry. & $\begin{array}{l}\text { Detailed theory. Numerous } \\
\text { computation tools are } \\
\text { available, and mostly suitable } \\
\text { for constructional material } \\
\text { science. }\end{array}$ \\
\hline
\end{tabular}

assumption for production and production-level software packages currently used for design in construction. If only macroscopic properties strength, modulus, Poisson ratio - are considered, than a lot of discrete models developed in applied mathematics (finite difference, finite element, boundary element, finite volume) can be applied for investigation of stressstrain state, acoustics, conservative transfer (heat, mass), hydrodynamics and aeroelasticity. 
Commercially available software packages for the first row of Table 1 often combine tools for many of the mentioned areas of application (so-called multiphysics solvers). At least, ANSYS Software suite [9], MSC Software suite [10] (Nastran, Dytran, Sinda etc.) and Abaqus [11] include solvers for all of the above areas. But these software suites are already based on results achieved in material science and mostly unsuitable during R\&D in material science.

The next two structural levels - macro- and microstructure - are of great interest for material scientists. The naming for second and third rows of Table 1 closely connected with concept widely accepted in constructional material science: the structural levels in building materials should be defined on the basis of dominant interaction type.

The coarse-grained structure of constructional mixtures and materials is mainly forming under influence of gravity; this level commonly referred as macrostructure. The structure of fine-grained part (binder, water and fine filler in case of cement composites; binder and fine filler in case of materials with polymer, bitumen and sulfur matrices) evolved under influence of forces caused by surface effects and surface energies. This level usually referred as microstructure. Exact spatial boundary between macro- and microstructure is not defined, but it is near $100 \mathrm{um}$.

Since at the macroscopic level the main type of interaction is the interaction caused by gravity force, the motion equations for elements of the system are simple. These are equations of classical mechanics. In constructional material science, the transient problem of structure formation process reflects technology of preparation and laying of constructional mix. If this problem is out of scope for the research, then modeling is often preformed only to determine the final configuration of coarse aggregates. The corresponding problems are theoretical examination and Monte Carlo simulation of dense packing in polydisperse systems, as well as percolation problems for frame of aggregates (the results can be used for prediction of mechanical properties) and pores (properties of porous space affects permeability and coupled properties - water, chemical and frost resistance). These problems has long history (at least, starting from early XX century, e.g. $[12,13])$.

The theoretical aspects for problem of packing of both polydisperse spheres and particles with complex shape were discussed in many research articles and scientific monographs. This is because method to design an 
ideal particle size distribution of constructional mix is extremely important for construction. The various geometric models were proposed, and different methods of percolation theory were then applied to the simulated packing [14-18].

Surprisingly, despite the great interest to the packing and percolation problems at the macroscopic level of constructional composite, there are no well known software tools for simulation in this area. Small tools for specific purposes and a few computational algorithms are created mostly by authors of algorithms. Such tools are of very limited scope of application, they use mutually incompatible formats of input and output data, realization of algorithms often is not verified extensively. In no conditions such software tools can be considered as production-ready, even if some of them proposed for commercial use (e.g. $[16,17])$. It seems that such situation for modeling the macroscopic level of constructional composite will last, though there are efforts directed to the unification of software tools and methods [7, 19] for modeling the macrostructure of constructional composites.

Modeling of the microstructure is more complicated in comparison with modeling of the upper structural level. To adequately represent the disperse system with fine filler, not only gravity force must be taken into account; moreover, gravity force can usually be ignored during numerical experiments. The primary forces caused by surface properties of the disperse phase and free energies on the inter-phase boundaries (interface energies; the wettability and contact angle are macroscopic properties tightly connected with these energies). Forces caused by surface effects and by external compaction pressure (if later is measured per one particle of the fine filler) may be of the same order of magnitude.

To take into account the surface effects, the model which is also based on classical mechanics have to include potential (force field) representing pairwise interaction. The derivative of pairwise potential along the direction between two particles is equal to binary forces acting between these particles; this force is then used during solution of the motion equations [7]. After the model is constructed and parameters of pairwise potential are determined, many existing software packages can be used for solution of ordinary differential equations (ODE) of motion. Wide availability of the software tools is due to rather curious fact that so-called $\mathrm{N}$-body problem (particle system with pairwise forces and classical equations of motion) 
was first occurred in completely different spatial scale, when motions of a group of celestial objects are studied. Thus, at present there are already a lot of efficient algorithms [20,21] and highly-optimized computer code [21] for the purpose. The comprehensive list of resources concerning software suitable for $\mathrm{N}$-body simulation can also be easily obtained [22].

At the same time, there are cases when pairwise forces between particles of the filler in constructional composite are too complex and depend not only on distance between surfaces of particles. Such cases can not be adequately handled by existing ODE software packages. Nevertheless, high availability and open source license for general-purpose numerical libraries allow to implement only «material science» part of the code - a part which is solely based on physical chemistry and thermodynamics, leaving the underlying mathematics aside.

There are also known extensions of the continuum mechanics which allow to perform constitutive modeling of heterogeneous multiphase materials. For example, Mori-Tanaka method [23, 24] can be used during simulation of stress-strain behavior in two-phase cases where volume fraction of one phase is significantly higher then volume fraction of the other.

The last (but not least) row of the Table 1 corresponds to atomistic scale. It is the domain of quantum mechanics: there are no particles; there are only waves and probability. Time-independent Schrödinger equation $H \psi=E \psi$ is very simple in form - it only states that valid energy $E$ must be eigenvalue of Hamiltonian $H$, and corresponding to this energy «shape of electron» («shape» of electron orbital) should be square $\psi \psi^{*}$ of the eigenfunction $\psi$ (wave function of electrons). The «solution» of the Schrödinger equation - even in time-independent case - is not simple, though. Numerous Nobel prizes were awarded for the process. The numerical methods, specifically designed for solution of Schrödinger equation, are implemented in software. The methods themselves often referred as quantum chemistry methods, and corresponding software is called quantum chemistry software.

Probably, the most famous open source package for quantum chemistry is General Atomic and Molecular Electronic Structure System (GAMESS) [25]. The code base of GAMESS was served as basis for some derivatives, for example FireFly [26]. Methods of quantum mechanics are also implemented in various multi-purpose commercial packages, notably Biovia (former Accelrys Materials Studio). The HyperChem [27] is the multi-purpose soft- 
ware package focused primarily on atomistic modeling and quantum chemistry computation. It allows to perform structure input, manipulation and display (GUI tools for creating and transforming structures, build clusters and complex molecular assemblies, import and export structures in different file formats - Brookhaven PDB, ChemDraw CHM, MOPAC Z-matrix, MDL MOL, ISIS Sketch, Tripos MOL2; parallel and perspective projections, highlighting hydrogen and van der Waals bonds, displaying dipole moment vectors), contain implementations of DFT and semi-empirical quantum algorithms, as well as implementations of molecular mechanics and mixed mode calculations.

And, finally, there is the fourth row of Table 1. This is nanoscale level and it was not previously defined at constructional material science at all. Here we are going to change the situation. Accordingly to the existing definitions of macro- and microstructure (which are only indirectly refer to the spatial scale), we will define nanostructure of constructional composite (which have not to be confused with general term "nanostructure») as a spatial level where properties of material are considerably affected by size effects. From now on there is no "gap" between microstructure of the filled binder and atomistic scale.

Quantum-chemical modeling can be used for predicting the interaction processes during structure formation of nanostructure. In [28], the HyperChem software was successfully used for quantum-chemical simulations of nanomodified polymeric composite material. During modeling the fragments imitating epoxy resin, hardener (polyethylene polyamine) and nanomodifiers were optimized. Than, absolute values of binding energy were calculated, the influence of fine suspensions of nanocomposites to the epoxy oligomer was modeled and simulation of the hardening process of nanocomposite was carried out. On the base of comparative analysis of the binding energies and electron densities authors stated that $\mathrm{NH}$ bond weakening takes place in case of presence of metal ions. The results obtained during modeling of hardening process allowed to claim that there is a self-organization process during the structure formation of epoxy composite. Such process is aftermath of introduction of metal-carbon nanosystem into the composite. The formation of metal coordination bond with nitrogen atom of the hardener can increase the polyamine activity during the hardening process [28].

In general, software tools for neighbor spatial scales can be utilized during investigation of nanostructure. For instance, modeling based on 
the analysis of the ensemble geometry is universal and can be applied on any structural level. In particular, authors of [29] had used this method in combination with Monte Carlo method for solution of percolation problem at nanoscale level. The obtained results concerning value of percolation threshold can successfully be used during development of building materials on upper spatial levels.

It must be stressed in conclusion, that while there are a lot of progress in development of modeling methods and software, the numerous particular problems arising during R\&D in constructional material science and nanotechnology of construction still require adequate solution. The system approach to the analysis of problem, followed by selection of proper modeling methods, algorithms and software tools, is the key for design of new efficient building materials.

\section{Dear colleagues!}

The reference to this paper has the following citation format:

Smirnov V.A., Korolev E.V., Evstigneev A.V. The review of the modeling methods and numerical analysis software for nanotechnology in material science. Nanotehnologii v stroitel'stve $=$ Nanotechnologies in Construction. 2014, Vol. 6, no. 5, pp. 34-58. Available at: http://nanobuild.ru/en_ $\mathrm{EN} /($ Accessed ). (In Russian). 


\section{References:}

1. Proshin A.P., Danilov A.M., Garkina I.A., Korolev E.V., Smirnov V.A. Synthesis of Special-purpose Building Materials on the Base of System Analysis. News of Higher Educational Institutions. Construction. 2003, no 7. pp. 43-47. (in Russian)

2. Korolev E.V., Samoshin A.P., Smirnov V.A., Koroleva O.V., Grishina A.N. Methods and synthesis algorithms of new-generation radiation-protective materials. Penza: PGUAS, 2009. 132 p. (in Russian)

3. Pommersheim J.M., Clifton J.R. Prediction of Concrete Service Life. Materials and Structures. 1985, Vol. 18, no. 1. pp. 21-30.

4. Bentz D.P., Peltz M.A., Snyder K.A., Davis J.M. VERDiCT: Viscosity Enhancers Reducing Diffusion in Concrete Technology. Concrete International. 2009. Vol. 31. pp. 31-36.

5. Korolev E.V., Smirnov V.A., Proshin A.P., Danilov A.M. Modeling of Evolution of Liophobic Disperse Systems. News of Higher Educational Institutions. Construction. 2004, no 8. pp. 32-38. (in Russian)

6. Proshin A.P., Danilov A.M., Korolev E.V., Smirnov V.A. Application of Dynamical Models for Examination of Cluster Forming in Composites. Asymptotic Systems. News of Higher Educational Institutions. Construction. 2003. no 3. pp. 32-38. (in Russian)

7. Smirnov V.A., Korolev E.V., Inozemtcev A.S. Dynamic Simulation of Nanoscale Systems. Nanotehnologii v stroitel'stve = Nanotechnologies in Construction. 2012, Vol. 4, no. 3.pp. 26-34. Available at: http://www.nanobuild.ru/en_EN (Accessed 30 Sep 2014). (In Russian)

8. Smirnov V.A., Korolev E.V. Nanomodified Epoxy Composites. Nanotehnologii v stroitel'stve $=$ Nanotechnologies in Construction. 2012, Vol. 4, no. 4. pp. 61-69. Available at: http://www.nanobuild.ru/en_EN (Accessed 30 Sep 2014). (In Russian)

9. Simulation Software - ANSYS. http://www.ansys.com/Products (Accessed 30 Sep 2014).

10. MSC Product Portfolio. http://www.mscsoftware.com/msc-product-portfolio (Accessed 30 Sep 2014).

11. Abaqus Portfolio - Dassault Systems. http://www.3ds.com/products-services/ simulia/portfolio/abaqus/abaqus-portfolio (Accessed 30 Sep 2014).

12. Fuller W.B., Thompson S.E. The laws of proportioning concrete. Trans. of American Society of Civil Engineers. 1907, Vol. 59. pp. 67-143.

13. Furnas C.C. Flow of gasses through beds of broken solids. Bureau of Mines Bulletin. 1929. $307 \mathrm{p}$.

14. Johansen V., Andersen P. Particle packing and concrete properties. In: Materials Science of Concrete II. Westerville: The American Ceramic Society. 1991. pp. 111-146. 
15. Stovall T., Larrard F., Buil M. Linear packing density model of grain mixtures. Powder Technology. 1986, Vol. 48. pp. 1-12.

16. Glavind M. Optimization of concrete work, Packing analysis as a tool for designing air void system. Summary Report. DTI Concrete Centre. 1997. (in Danish)

17. Glavind M., Pedersen E.J. Packing calculations applied for Concrete Mix Design. Proc. In. Conf. Creating with Concrete, University of Dundee. 1999. pp. 1-10.

18. Raj N., Patil S., Bhattacharjee B. Concrete Mix Design by Packing Density Method. IOSR Journal of Mechanical and Civil Engineering. 2014, Vol. 11, no. 2. pp. 34-46.

19. Smirnov V.A., Korolev E.V., Inozemtcev S.S. Stochastic Simulation of Nanoscale Systems. Nanotehnologii v stroitel'stve = Nanotechnologies in Construction. 2012, Vol. 4, no. 1.pp.6-14. Available at: http://www.nanobuild.ru/en_EN (Accessed 30 Sep 2014). (In Russian)

20. Haile J.M. Molecular dynamics simulation. NY.: Wiley, 1997. 512 p.

21. Press W.H., Teukolsky S.A., Vetterling W.T., Flannery B.P. Numerical Recipes in C: The Art of Scientific Computing. NY.: Cambridge University Press, 1992. 965 p.

22. Google search query «List of N-body simulation software». https://www.google. $\mathrm{ru} /$ search? $\mathrm{q}=$ list + of $+\mathrm{n}$-body + simulation + software (Accessed 30 Sep 2014).

25. Gordon Group/GAMESS. http://www.msg.ameslab.gov/gamess (Accessed 30 Sep 2014).

26. Firefly (formerly PC GAMESS) Home Page. http://classic.chem.msu.su/gran/ gamess

27. Features of HyperChem. URL: http://www.hyper.com

28. Chashkin M.A., Kodolov V.I., Zakharov A.I., Vasilchenko Yu.M., Vakhrushina M.A., Trineeva V.V., Zaikov G.E. Quantum - Chemical Modeling. In: Handbook of Research on Functional Materials: Principles, Capabilities and Limitations. Ed. by Wilkie C., Geuskens G., Lobo V. Oakville: Apple Academic Press. 2014. p. 344-359

29. Smirnov V.A., Korolev E.V., Albakasov A.I. Size Effects and Topological Characteristics of Nanomodified Composites. Nanotehnologii v stroitel'stve $=$ Nanotechnologies in Construction. 2011, Vol. 3, no. 4. pp. 17-27. Available at: http://www. nanobuild.ru/en_EN (Accessed 30 Sep 2014). (In Russian) 